\title{
Are depressive residual symptoms independent of treatments?
}

\author{
Maria Luisa Figueira \\ From $1^{\text {st }}$ International Congress on Neurobiology and Clinical Psychopharmacology and European \\ Psychiatric Association Conference on Treatment Guidance \\ Thessaloniki, Greece. 19-22 November 2009
}

Residual symptoms occur in many depressive patients after acute treatment [1]. There is growing evidence that residual symptoms are also prevalent in bipolar disorder during the euthymic phase and in unipolar depression, they are predictors of early relapse $[2,3]$. In long-term outcome, patients remitting from depression with residual symptoms, have more depressive symptoms and impaired social functioning, thus needing more aggressive treatment [4]. Residual symptoms might be conceived as the persistence of the original mood disorder, despite in a milder presentation, or still be in relation to the neurobiological disorder substrate. Residual symptoms include core mood and functional symptoms of depression. The most common residual symptoms are sleep disturbances, fatigue, and disinterest. The clinician should be aware that patients despite being in apparent remission should be questioned thoroughly in order to identify residual cognitive difficulties, impairment of work and activities, psychic anxiety, sleep disturbances or mild depressive mood [5]. The consequences of lowquality remission impairing psychosocial functioning have to be emphasized. In this presentation we will review the available evidence of the role played by the pharmacological treatments in the residual depressive symptoms.

Published: 22 April 2010

\section{References}

1. Fava GA, Fabbri S, Sonino N: Residual symptoms in depression: an emerging therapeutic target. Prog Neuropsychopharmacol Biol Psychiatry 2002, 26(6):1019-27.

2. Paykel ES, Abbott R, Morriss R, Hayhurst $H$, Scott J: Sub-syndromal and syndromal symptoms in the longitudinal course of bipolar disorder. $\mathrm{Br} J$ Psychiatry 2006, 189:118-23.

Faculty of Medicine, University of Lisbon, and Head of the Psychiatric Department Hospital Santa Maria, University of Lisbon, Portugal
3. Paykel ES, Ramana R, Cooper Z, Hayhurst H, Kerr J, Barocka A: Residual symptoms after partial remission: an important outcome in depression. Psychol Med 1995, 25(6):1171-80.

4. Kennedy N, Paykel ES: Residual symptoms at remission from depression: impact on long-term outcome. J Affect Disord 2004, 80(2-3):135-44.

5. Paykel ES: Partial remission, residual symptoms, and relapse in depression. Dialogues Clin Neurosci 2008, 10(4):431-7.

doi:10.1186/1744-859X-9-S1-S72

Cite this article as: Figueira: Are depressive residual symptoms independent of treatments?. Annals of General Psychiatry 2010 9(Suppl 1): S72.
Submit your next manuscript to BioMed Central and take full advantage of:

- Convenient online submission

- Thorough peer review

- No space constraints or color figure charges

- Immediate publication on acceptance

- Inclusion in PubMed, CAS, Scopus and Google Scholar

- Research which is freely available for redistribution

Submit your manuscript at www.biomedcentral.com/submit
C BioMed Central 